\title{
Postnatal depressive features in mothers of neonates admitted to a neonatal unit at Steve Biko Academic Hospital: The role of sociodemographic and psychosocial factors
}

\author{
B Mnisi, ${ }^{1}$ MB ChB; J Makin,,${ }^{1,2}$ BSc Hons; B G Lindeque, ${ }^{1} \mathrm{MD}$; S Adam, ${ }^{1} \mathrm{PhD}$ \\ ${ }^{1}$ Department of Obstetrics and Gynaecology, Faculty of Health Sciences, University of Pretoria, South Africa, \\ ${ }^{2}$ Medical Research Unit for Maternal and Infant Health Care Strategies, University of Pretoria, South Africa
}

Corresponding author: S Adam (sumaiya.adam@up.ac.za)

Background. Postnatal depression (PND) is one of the most common complications following delivery. The development of PND is closely linked with biological, psychological, socioeconomic and cultural factors.

Objectives. To determine the prevalence and identify risk factors for PND in mothers delivering at Steve Biko Academic Hospital (SBAH) whose babies were admitted to the neonatal unit.

Methods. We conducted a prospective observational study at SBAH, Pretoria, South Africa (SA). Women who delivered between 26 and 42 weeks' gestation at SBAH and whose babies were admitted to the neonatal unit were recruited at delivery. Interview screening using the Edinburgh Postnatal Depression Scale (EPDS) was conducted regarding the mother's experience of her pregnancy and delivery. Sociodemographic and psychosocial data from the mothers were included in a multiple logistic regression model to estimate association with PND symptoms.

Results. Between 11 March and 30 December 2017, 2671 mothers delivered at SBAH. Of these, 196 (7.3\%) babies were admitted to the neonatal intensive care unit (NICU) and $10(0.3 \%)$ were admitted to the neonatal high care unit (NHC). Mothers' accommodation during their babies' admission to the neonatal unit $(p=0.002)$, having poor interpersonal relationships $(p<0.0001)$, and intimate partner violence (IPV) $(p=0.004)$ were significantly associated with screening positive for PND.

Conclusion. Accommodation during neonatal care, availability of counselling, inclusion of the partner in postnatal care and IPV are significant factors in the depressive symptoms experienced by mothers postpartum in this setting.

S Afr J Obstet Gynaecol 2019;25(3):89-94. https://doi.org/10.7196.SAJOG.2019.v25i3.1467

Postnatal depression (PND) is one of the most common complications affecting women following delivery. It is characterised by physiological and psychological symptoms and signs in women four to six weeks after giving birth. ${ }^{[1]}$ It is a major public health issue in western economically developed societies, affecting $10-15 \%$ of mothers postpartum. ${ }^{[1,2]}$ The prevalence of PND in South Africa (SA) is high, but there is a lack of data on PND among HIV-infected women specifically. ${ }^{[2]}$

Postpartum psychiatric disorders range from mild and common postpartum 'blues' to the much rarer incidence of severe postpartum psychosis ${ }^{[3]}$ The prevalence of PND appears to vary greatly from site to site. Figures from developed countries indicate a rate of $10-15 \%{ }^{[1]}$ but in a review of 143 studies comprising 40 developed and developing countries by Norhayati et al. ${ }^{[4]}$ there was a reported prevalence ranging from 0 to $60 \%{ }^{[4]}$ Antenatal depression is the strongest predictor of PND. ${ }^{[5]}$

Variation in the incidence of PND may be explained by various factors including the time point of evaluation, the assessment tool or diagnostic criteria used, differences in biological vulnerability and differences in socioeconomic environment and cultural backgrounds. ${ }^{[5]}$ Therefore, the determination of the prevalence of and risk factors for PND across different cultures may help identify women at risk and provide evidence for early interventional strategies. Recently there has been growing interest regarding the risk factors of PND, though the aetiology of PND remains unclear. ${ }^{[5]}$ The development of PND is closely linked with biological, psychological, socioeconomic and cultural factors. ${ }^{[6,7]}$ Pre-natal depression is the most consistent risk factor that predicts the severity of PND. ${ }^{[2,6,7]}$ Preterm infants account for up to $70 \%$ of neonatal mortality and morbidity, which can cause significant maternal stress because of the infant's uncertain health. ${ }^{[6,7]}$ The risk of anxiety is 2.7 times greater in mothers of preterm infants than those of term infants. ${ }^{[8,9]}$ In addition, chronic prenatal pain, pregnancy loss, living in urban areas, low self-esteem, lack of social support, unplanned pregnancies, low socio-economic status, parttime employment, being left alone in labour and marital conflict are the most common risk factors for PND. ${ }^{[8,9]}$ PND has detrimental effects on mothers and their partners, and on the interaction between mother and child as well as the mental development of the child. PND is associated with low quality of life and poor mental health in mothers. ${ }^{[10,11]}$ PND also has pervasive effects on mother-infant bonding in the short term and affects the emotional, cognitive and behavioural development of the child. ${ }^{[10,11]}$ In longterm follow-up studies, PND is associated with an increased risk for psychiatric disorders in the offspring during adolescence. ${ }^{[12]}$ Most surveys and epidemiological studies focused on the prevalence and related factors of PND in western industrialised societies where women at risk are often recognised. ${ }^{[6,7,9]}$ Therefore, there is a 
need to evaluate the incidence of PND and its culturally-sensitive correlates in developing countries. Furthermore, there is a need to assess the impact of distinct environmental and cultural norms on PND. For example, PND is less prevalent within some traditional cultural settings, where a woman tends to rest in bed for four weeks after giving birth, while the womens' mothers or relatives attend to household issues and childcare. ${ }^{[13]}$ The aims of the present study were to determine the prevalence and identify risk factors for postpartum depression in mothers delivering at Steve Biko Academic Hospital (SBAH), Pretoria, South Africa (SA) whose babies were admitted to either the neonatal intensive care (NICU) or neonatal high care units (NHC).

\section{Methods}

A prospective observational study was conducted at SBAH between 11 March 2017 and 30 December 2017. SBAH is a tertiary hospital that has a high-risk obstetric unit. Mothers delivering between 26 and 42 weeks' gestation at SBAH whose babies were admitted to either the NICU or NHC were eligible for recruitment at delivery. Mothers who consented to participate in the study were interviewed regarding their experience of pregnancy and delivery. They were screened for depression at recruitment using the Edinburgh Postnatal Depression Scale (EPDS), ${ }^{[14]}$ Intimate partner violence (IPV) screen (Hurt, Insulted, Threatened with Harm and Screamed (HITS)), ${ }^{[15]}$ and Interpersonal Support Evaluation List (ISEL-12). ${ }^{[16]}$ Sociodemographic and psychosocial data were simultaneously captured. At 6 weeks post-delivery, mothers were re-interviewed and re-screened for PND either at the postnatal clinic or telephonically, using the aforementioned tools. An EPDS score $\geq 12$ was regarded as screen positive for PND and the participant was referred to a psychologist or psychiatrist. The HITS domestic violence screening score ${ }^{[15]}$ was used to screen for IPV. A score $\geq 10$ was regarded as a positive screen and the mother was referred to a social worker. We used the ISEL-12 $2^{[16]}$ to evaluate the mother's perceived social support, i.e. the availability of and potential for social interaction and support. The ISEL-12 includes sub-scales: (i) tangible evaluates the perceived availability of material aid; (ii) appraisal assesses the perceived availability of people with whom one can share one's problems; and (iii) belonging assesses the perceived availability of people with whom one can engage in activities. Low scores indicate poor social support.

\section{Data analysis}

The data were analysed using SPSS software (IBM Corp., USA). Frequency distributions, means, ranges and standard deviations were used to describe measured variables in the study population. ISEL-12 was analysed as a holistic scale as well as by each subscale, i.e. tangible, appraisal and belonging. Bivariate analysis was used to determine if women with symptoms of PND (EPDS $\geq 12$ ) differ significantly from women without PND symptoms based on demographic and psychosocial factors. All factors were included in a multiple logistic regression model to estimate the association with PND symptoms. Statistical significance was set at $\leq 0.05$. We also examined which combination of demographic and psychosocial factors were found to best predict PND symptoms in a logistic regression model. The study was approved by the University of Pretoria Health Sciences Research Ethics Committee (ref. no. 2016-0257).

\section{Results \\ Study participant characteristics}

In the study period of 11 March 2017 to 30 December 2017, 2671 mothers delivered at SBAH. Table 1 details the demographic information of 206 (7.7\%) mothers who consented to and were included in the study. A total of 196 mothers (7.3\%) had neonates admitted to NICU and $10(0.3 \%)$ were admitted to NHC (Fig. 1). Table 2 details the perinatal factors and pregnancy outcomes. Most babies were admitted with the problems of prematurity and related respiratory distress syndrom (RDS) (66\%). Approximately half the mothers were unmarried and 19 (9.2\%) reported being unaccompanied by partners or doulas to the delivery rooms. Twenty-five percent of mothers reported that they did not see their babies at birth. Most mothers were HIV-negative (60.7\%), had unplanned pregnancies $(80.6 \%)$, stayed at the mother lodger facility post-delivery $(80.6 \%)$ and opted to breastfeed their infants (70.9\%). Ninety-seven mothers (47.1\%) reported having an underlying medical condition such as hypertension, diabetes mellitus and asthma. About $50 \%$ of mothers reached secondary education level, while only $39 \%$ completed tertiary level. There was an unemployment rate of $64.6 \%$ in the study population. Among those who were employed (35.4\%), only $32 \%$ earned more than ZAR2 500 per month, which was below the minimum wage at the time of the study.

\section{Factors associated with increased risk of PND}

Ninety women (43.7\%) screened positive (score $>12$ ) on the EDPS and of these, 87 (42.2\%) had babies admitted to NICU, with 3 (1.4\%) admitted to the HCU. Table 3 compares mothers who screened positive with those that screened negative on the Edinburgh Postnatal depression score. Overall, there was no significant difference between the reason for admission and the risk of PND (screen positive on EPDS). Shona, the Zimbabwean language, accounted for $11.7 \%$ of the languages spoken by mothers delivered and admitted to the unit. Shona was more common than any other SA languages except Afrikaans. However, this was not a risk for PND ( $p=0.478)$, but might have had an impact on support structures. The factors significantly associated with PND were mothers' accommodation during the baby's admission to the neonatal unit $(p=0.002)$, having poor interpersonal relationships as assessed by the ISEL $(p<0.0001)$, and IPV was determined by the HITS score $(p=0.004)$. When these factors were included in a logistic regression model, having poor interpersonal relationships was the only factor that remained significant $(p<0.0001)$.

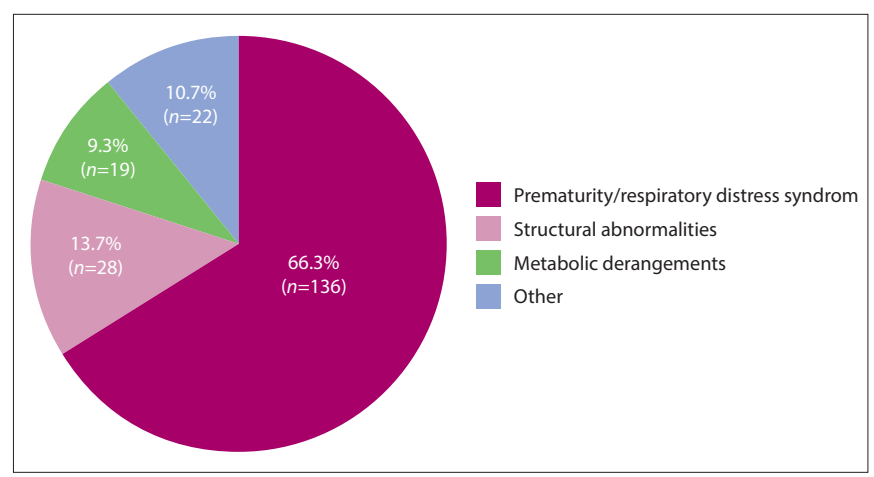

Fig. 1. Indications for admission to neonatal intensive care unit and high care unit. 


\section{RESEARCH}

Table 1. Description of the mothers of babies admitted to the neonatal unit

\begin{tabular}{|c|c|c|c|}
\hline Characteristic & Total $(N=206), n(\%)^{*}$ & NICU admission $(N=196), n(\%)^{*}$ & HCU admission $(N=10), n(\%)^{\star}$ \\
\hline Mean age, years (range) & $27.96(17-41)$ & $28.2(17-44)$ & $30.4(19-41)$ \\
\hline \multicolumn{4}{|l|}{ HIV status } \\
\hline Negative & $125(60.7)$ & $121(58.7)$ & $6(66.7)$ \\
\hline Positive & $81(39.3)$ & $78(37.3)$ & $3(33.3)$ \\
\hline \multicolumn{4}{|l|}{ Medical conditions } \\
\hline Yes & $97(47.1)$ & $91(44.1)$ & $6(66.7)$ \\
\hline No & $109(52.9)$ & $106(51.4)$ & $3(33.3)$ \\
\hline \multicolumn{4}{|l|}{ Planned pregnancy } \\
\hline Yes & $40(19.4)$ & $61(29.6)$ & $5(2.4)$ \\
\hline No & $166(80.6)$ & $135(66)$ & $4(1.9)$ \\
\hline \multicolumn{4}{|l|}{ Difficulty in conceiving } \\
\hline Yes & $40(19.4)$ & $36(17.4)$ & $4(1.9)$ \\
\hline No & $166(80.6)$ & $161(78.1)$ & $5(2.4)$ \\
\hline \multicolumn{4}{|l|}{ Home language } \\
\hline English & $19(9.2)$ & $18(8.7)$ & $1(0.4)$ \\
\hline Afrikaans & $37(18)$ & $36(17.5)$ & $1(0.4)$ \\
\hline Tswana & $9(4.4)$ & $9(4.4)$ & 0 \\
\hline Zulu & $22(10.7)$ & $22(10.7)$ & 0 \\
\hline Swati & $9(4.4)$ & $8(3.9)$ & $1(0.4)$ \\
\hline Ndebele & $7(3.4)$ & $7(3.4)$ & 0 \\
\hline Tsonga & $21(10.2)$ & $20(9.7)$ & $1(0.4)$ \\
\hline Sepedi & $42(20.4)$ & $41(19.9)$ & $1(0.4)$ \\
\hline Venda & $6(2.9)$ & $6(2.9)$ & 0 \\
\hline isiXhosa & $9(4.4)$ & $9(4.4)$ & 0 \\
\hline Shona & $24(11.7)$ & $22(10.7)$ & $2(0.9)$ \\
\hline Portuguese & $1(0.5)$ & $0(0.0)$ & $1(0.4)$ \\
\hline \multicolumn{4}{|l|}{ Relationship status } \\
\hline Divorced/single & $19(9.2)$ & $15(7.2)$ & $4(1.9)$ \\
\hline In a relationship & $109(52.9)$ & $106(51.4)$ & $3(1.4)$ \\
\hline Married & $78(37.9)$ & $74(35.9)$ & $4(1.9)$ \\
\hline \multicolumn{4}{|l|}{ Living with partner } \\
\hline Yes & $117(56.8)$ & $113(54.0)$ & $4(1.9)$ \\
\hline No & $88(42.9)$ & $83(40.0)$ & $5(2.4)$ \\
\hline \multicolumn{4}{|l|}{ Education } \\
\hline Primary & $21(10.2)$ & $18(8.7)$ & $3(1.4)$ \\
\hline Secondary & $103(50.0)$ & $98(47.0)$ & $5(2.4)$ \\
\hline Tertiary & $82(39.8)$ & $81(39.0)$ & $1(0.4)$ \\
\hline \multicolumn{4}{|l|}{ Employment } \\
\hline Yes & $73(35.4)$ & $71(34.0)$ & $2(0.9)$ \\
\hline No & $133(64.6)$ & $123(59.7)$ & $7(3.3)$ \\
\hline \multicolumn{4}{|l|}{ Income, ZAR } \\
\hline$<2500$ & $5(2.4)$ & $2(0.9)$ & $3(1.4)$ \\
\hline$\geq 2500$ & $66(64.6)$ & $60(29)$ & $6(2.9)$ \\
\hline
\end{tabular}

\section{Discussion}

PND is a significant health concern. Prevalence rates of up to $30 \%$ have been reported in SA. ${ }^{[1,20]}$ Rates of postpartum depression are even higher in mothers whose infants are admitted to a neonatal unit and have a prolonged hospitalisation and medical intervention. ${ }^{[6,7,17]}$ For those mothers who experience considerable stress, anxiety and depression, demographic and psychosocial factors may further put them at risk for postnatal depression. Furthermore, in low-to-middle income countries, being the victims of IPV, being socially disadvantaged and receiving poor social support may further exacerbate the symptoms of PND. ${ }^{[1,11,13,18]}$

Identifying women who may be at increased risk for PND is an important clinical goal. Despite growing knowledge that PND is a major childbirth complication, postpartum depression screening is not yet included in the standard of care in the USA or in SA. Although there are various studies on PND in an SA population, none of these studies have focused on the mothers whose infants require neonatal care. ${ }^{[19-21]}$ It is known that mothers whose newborns are admitted to NICE are more stressed about uncertainty regarding their newborn babies. ${ }^{[22,23]}$

In the present study, we demonstrated that the mother's place of accommodation, having poor interpersonal relationships and history of prior exposure to IPV played a key role in putting mothers at increased risk for postpartum depression. Other studies highlighted factors such as antenatal depression as a paramount factor responsible for postpartum depression in most cases, but this was not demonstrated in our study. ${ }^{[4,6]}$ In addition, being unmarried, unemployed, and having underlying medical conditions 
RESEARCH

\begin{tabular}{|c|c|c|c|}
\hline Characteristic & $\operatorname{Total}(N=206), n(\%)^{*}$ & NICU admission $(N=196), n(\%)^{*}$ & HCU admission $(N=9), n(\%)^{*}$ \\
\hline \multicolumn{4}{|l|}{ Antenatal complications } \\
\hline Yes & $71(34.5)$ & $64(32.7)$ & $6(6.7)$ \\
\hline No & $135(65.5)$ & $132(67.3)$ & $3(3.3)$ \\
\hline Mean GA at delivery, weeks (range) & $34.65(26-41)$ & $34(26-41)$ & $36.6(27-41)$ \\
\hline \multicolumn{4}{|l|}{ Mode of delivery } \\
\hline NVD & $141(68.4)$ & $143(69)$ & $4(44.4)$ \\
\hline Caesarean section & $58(28.2)$ & $55(26)$. & $3(33.3)$ \\
\hline Instrumental delivery & $7(3.4)$ & $3(1.4)$ & $2(22.2)$ \\
\hline \multicolumn{4}{|l|}{ Intrapartum problems } \\
\hline Yes & $80(38.8)$ & $75(36.4)$ & $5(2.4)$ \\
\hline No & $126(61.2)$ & $122(59.2)$ & $4(1.9)$ \\
\hline \multicolumn{4}{|l|}{ Someone present during birth ${ }^{\dagger}$} \\
\hline Yes & $187(90.8)$ & $159(77.1)$ & $8(3.8)$ \\
\hline No & $19(9.2)$ & $18(8.7)$ & $1(0.4)$ \\
\hline Mean birthweight, g (range) & $\begin{array}{l}2268 \\
(500-4400)\end{array}$ & $\begin{array}{l}2295 \\
(500-4200)\end{array}$ & $\begin{array}{l}2322 \\
(830-4400)\end{array}$ \\
\hline \multicolumn{4}{|l|}{ Apgar score at $5 \mathrm{~min}$} \\
\hline$<7$ & $52(25.9)$ & $42(20.3)$ & $5(2.4)$ \\
\hline$\geq 7$ & $93(45.1)$ & $92(44.6)$ & $2(0.97)$ \\
\hline Unknown & & $72(59.0)$ & $2(0.97)$ \\
\hline \multicolumn{4}{|l|}{ Saw baby at birth } \\
\hline Yes & $153(74.3)$ & $149(72.3)$ & $4(1.94)$ \\
\hline No & $53(25.7)$ & $43(20.8)$ & $5(2.4)$ \\
\hline \multicolumn{4}{|l|}{ Infant feeding } \\
\hline Breastmilk & $146(70.9)$ & $141(68.4)$ & $5(2.4)$ \\
\hline Expressed breastmilk & $46(22.3)$ & $43(20.4)$ & $3(1.4)$ \\
\hline Bottle/formula & $14(6.8)$ & $13(6.3)$ & $1(0.4)$ \\
\hline \multicolumn{4}{|l|}{ Accommodation during baby admission } \\
\hline Inpatient & $32(15.5)$ & $31(15)$ & $1(0.4)$ \\
\hline Lodger & $166(80.6)$ & $158(76.6)$ & $8(3.8)$ \\
\hline Home & $8(3.9)$ & $8(3.8)$ & 0 \\
\hline
\end{tabular}

are also known risk factors which were not found in the study population..$^{[4,6]}$

Prenatal assessment for PND risk is an imprecise endeavour. At present, no reliable, valid, prenatal screening instrument is available for routine use. ${ }^{[4]}$ The use of assessment measures and clinical interviewing may detect known prenatal risk factors and depressive symptoms. Therefore, a two-pronged approach to identify pregnant women at risk of PND is recommended: identification of PND risk factors and current psychosocial situation in the health history, followed by a depression symptom assessment. The 10-item EPDS-10 was validated and found to be effective in the SA population. ${ }^{[14,21]}$ Universal screening for PND comes with a financial implication and an increased burden to healthcare workers. Sub-population screening can be more cost-effective in the short term, but the challenge of missing mothers at risk of developing depression while no antenatal risk factors remains. ${ }^{[2]}$ The effects of PND on the mother, her marital relationship, and her children make it an important condition to diagnose, treat and prevent. ${ }^{[10,11,18,24,25]}$ If postpartum depression is to be prevented by clinical or public health intervention, its risk factors need to be reliably identified. Postpartum depression is often treated with psychotherapy (also called talk therapy or mental health counselling), medication or both. Mothers may find it helpful to talk through their concerns with a psychiatrist, psychologist or other mental health professional. Therapy can assist mothers with finding better ways to cope with their feelings, solve problems, set realistic goals and respond to situations in a positive way. Sometimes family or relationship therapy also helps. Antidepressants can be used with caution if a mother is breastfeeding. ${ }^{[3,9,26]}$ Untreated postpartum depression can lead to an increase in suicide and postpartum psychosis. In addition, untreated postpartum depression has a negative impact on future generations. ${ }^{[27]}$

In addition to the classical symptomatology associated with major depressive episodes, women with PND often report having a lack of confidence in their ability to take care of their children. Sleep disturbances and fatigue are common after childbirth and during the postpartum period, making it harder to diagnose PND. ${ }^{[27]}$ Consequently, a large percentage $(\sim 50 \%)$ of PND cases remain undetected. ${ }^{[28]}$ Some biological risk factors for PND have been identified including genetic and epigenetic factors and endocrine deregulations. ${ }^{[4-6]}$ Many sociodemographic and psychosocial characteristics as well as psychiatric disorders have been associated with PND in the literature. ${ }^{[4-6,28]}$

The duration of postpartum depression varies from study to study, with some authors finding that postpartum depression had remitted by $4-12$ months. ${ }^{[29]}$ Cooper et al. ${ }^{[30]}$ found a PND rate of $35 \%$ in a group of 147 women in Khayelitsha, Cape Town, SA who had delivered two months earlier. ${ }^{[30]}$ Others found that $14 \%$ still had symptoms at 1 year postpartum and others found that more women were depressed at 9 months postpartum than at 3 months. ${ }^{[31,32]}$

\section{Conclusion}

In this study, we found that the majority of mothers who scored 13 and more on the EDPS were those admitted to mother lodger facilities while their babies were admitted to NICU. Our study 
RESEARCH

Table 3. Comparison of mothers based on the EDPS

\begin{tabular}{|c|c|c|c|}
\hline Characteristic & EPDS $\leq 12(N=116), n(\%)^{*}$ & EPDS $>12(N=90), n(\%)^{*}$ & $p$-value \\
\hline Mean age, years (range) & $28.4(18-41)$ & $7.4(18-41)$ & 0.541 \\
\hline Parity, mean (range) & $1.72(0-6)$ & $1.58(0-6)$ & 0.133 \\
\hline Mean GA at delivery, weeks (range) & $34.4(26-41)$ & $34.8(26-41)$ & 0.184 \\
\hline $\begin{array}{l}\text { Mode of delivery } \\
\text { NVD } \\
\text { Caesarean section } \\
\text { Instrumental delivery }\end{array}$ & $\begin{array}{l}76(65.4) \\
36(31.0) \\
4(3.4)\end{array}$ & $\begin{array}{l}65(72.2) \\
22(24.4) \\
3(3.3)\end{array}$ & 0.545 \\
\hline Mean birthweight, g (range) & $2100(830-3400)$ & $2400(830-3400)$ & 0.753 \\
\hline $\begin{array}{l}\text { HIV status } \\
\text { Negative } \\
\text { Positive }\end{array}$ & $\begin{array}{l}70(60.3) \\
46(39.7)\end{array}$ & $\begin{array}{l}52(25.0) \\
38(18.0)\end{array}$ & \\
\hline $\begin{array}{l}\text { Medical conditions } \\
\text { Yes } \\
\text { No }\end{array}$ & $\begin{array}{l}51(44.0) \\
65(56.0)\end{array}$ & $\begin{array}{l}46(51.1) \\
44(48.9)\end{array}$ & 0.308 \\
\hline $\begin{array}{l}\text { Apgar score at } 5 \mathrm{~min}^{5} \\
\quad<7 \\
\geq 7\end{array}$ & $\begin{array}{l}59(57.0) \\
29(33.0)\end{array}$ & $\begin{array}{l}34(59.6) \\
23(40.4)\end{array}$ & 0.364 \\
\hline $\begin{array}{l}\text { Saw baby at birth } \\
\text { Yes } \\
\text { No }\end{array}$ & $\begin{array}{l}86(74.1) \\
30(25.9)\end{array}$ & $\begin{array}{l}67(74.4) \\
23(25.6)\end{array}$ & 0.960 \\
\hline $\begin{array}{l}\text { Planned pregnancy } \\
\text { Yes } \\
\text { No }\end{array}$ & $\begin{array}{l}41(35.3) \\
75(64.7)\end{array}$ & $\begin{array}{l}25(27.8) \\
65(72)\end{array}$ & 0.248 \\
\hline $\begin{array}{l}\text { Perceived fertility problems } \\
\text { Yes } \\
\text { No }\end{array}$ & $\begin{array}{l}21(18.1) \\
95(81.9)\end{array}$ & $\begin{array}{l}19(21.1) \\
71(78.9)\end{array}$ & 0.588 \\
\hline $\begin{array}{l}\text { Antenatal problems } \\
\text { Yes } \\
\text { No }\end{array}$ & $\begin{array}{l}38(32.8) \\
78(67.2)\end{array}$ & $\begin{array}{l}33(36.7) \\
57(63.3)\end{array}$ & 0.558 \\
\hline $\begin{array}{l}\text { Intrapartum problems } \\
\text { Yes } \\
\text { No }\end{array}$ & $\begin{array}{l}39(33.6) \\
77(66.4)\end{array}$ & $\begin{array}{l}41(45.6) \\
49(54.4)\end{array}$ & 0.081 \\
\hline $\begin{array}{l}\text { Someone present during birth } \\
\text { Yes } \\
\text { No }\end{array}$ & $\begin{array}{l}105(90.5) \\
11(9.5)\end{array}$ & $\begin{array}{l}82(91.1) \\
8(8.9)\end{array}$ & 0.884 \\
\hline $\begin{array}{l}\text { Where are you staying? } \\
\text { Inpatient } \\
\text { Lodger ward } \\
\text { Home }\end{array}$ & $\begin{array}{l}23(19.8) \\
85(73.3) \\
8(6.9)\end{array}$ & $\begin{array}{l}9(10.0) \\
81(90.0) \\
0\end{array}$ & 0.002 \\
\hline $\begin{array}{l}\text { Infant feeding } \\
\text { Breastmilk } \\
\text { Bottle/formula }\end{array}$ & $\begin{array}{l}96(82.8) \\
10(8.6)\end{array}$ & $\begin{array}{l}86(95.6) \\
4(4.4)\end{array}$ & 0.487 \\
\hline $\begin{array}{l}\text { Relationship status } \\
\text { Divorced /single } \\
\text { In a relationship } \\
\text { Married }\end{array}$ & $\begin{array}{l}8(6.9) \\
64(55.2) \\
44(37.9)\end{array}$ & $\begin{array}{l}11(12.2) \\
35(50.0) \\
34(37.8)\end{array}$ & 0.404 \\
\hline $\begin{array}{l}\text { Living with partner } \\
\text { Yes } \\
\text { No }\end{array}$ & $\begin{array}{l}81(39.3) \\
3(1.4)\end{array}$ & $\begin{array}{l}30(14.5) \\
2(0.9)\end{array}$ & 0.236 \\
\hline $\begin{array}{l}\text { Education } \\
\text { Primary } \\
\text { Secondary } \\
\text { Tertiary }\end{array}$ & $\begin{array}{l}8(6.9) \\
59(50.9) \\
49(42.2)\end{array}$ & $\begin{array}{l}13(14.4) \\
44(48.9) \\
33(36.7)\end{array}$ & 0.195 \\
\hline $\begin{array}{l}\text { Employment } \\
\text { Yes } \\
\text { No }\end{array}$ & $\begin{array}{l}37(31.9) \\
79(68.1)\end{array}$ & $\begin{array}{l}36(40.0) \\
54(60.0)\end{array}$ & 0.228 \\
\hline $\begin{array}{l}\text { Income, ZAR } \\
\quad<2500 \\
\quad \geq 2500\end{array}$ & $\begin{array}{l}2(5.7) \\
33(94.3)\end{array}$ & $\begin{array}{l}3(8.3) \\
33(91.3)\end{array}$ & 1 \\
\hline HITS score, mean (SD) & $8.4(18.0)$ & $8.3(2.5)$ & 0.004 \\
\hline ITS list, mean (SD) & $35.8(3.1)$ & $32.6(4.2)$ & $<0.0001$ \\
\hline
\end{tabular}


further demonstrated that a lack of interpersonal support and a history of prior exposure to IPV were contributory to the development of PND features.

It is of paramount importance that the motehr's accommodation facilities are modified or improved to provide a safer, more conducive environment for mothers. We need to develop a strategy to incorporate family members (in particular partners/husbands) to be actively involved in supporting their pregnant partners during the antepartum and postpartum periods. This will assist in reducing the high incidence of antepartum depression, which seems to be a persistent risk factor contributory to the development of PND.

\section{Acknowledgements. None.}

Author contributions. RM was responsible for protocol development, data collection and manuscript compilation. JDM was responsible for statistical analysis. BGL was responsible for manuscript compilation. SA was responsible for the developing the concept, protocol development and manuscript compilation.

\section{Funding. None.}

\section{Conflicts of interest. None.}

1. Shorey S, Chee CYI, Ng ED, Chan YH, Tam WWS, Chong YS. Prevalence and incidence of postpartum depression among healthy mothers: A systematic review and meta-analysis. J Psychiatr Res 2018;104:235-248. https://doi.org/10.1016/j.jpsychires.2018.08.001

2. Nakku JE, Nakasi G, Mirembe F. Postpartum major depression at six weeks in primary health care prevalence and associated factors. Afr Health Sci 2006;6(4):207-214

3. Rai S, Pathak A, Sharma I. Postpartum psychiatric disorders: Early diagnosis and management Indian J Psychiatry 2015;57(Suppl 2):S216-S221. https://doi.org/10.4103/0019-5545.161481

4. Norhayati MN, Nik Hazlina NH, Asrenee AR, Wan Emilin WMA. Magnitude and risk factors for postpartum symptoms: A literature review. J Affect Disord 2015;175:34-52. https://doi. org/10.1016/j.jad.2014.12.041

5. Rich-Edwards JW, Kleinman K, Abrams A, et al. Sociodemographic predictors of antenatal and postpartum depressive symptoms among women in a medical group practice. J Epidemio Community Health 2006;60:221-227. https://doi.org/10.1136/jech.2005.039370

6. O'Hara M, Swain A. Rates and risk of postpartum depression: A meta-analysis. Intl Rev Psychiatr 1996;8(1):37-54. https://doi.org/10.3109/09540269609037816

7. Josefsson A, Berg G, Nordin C, Sydsjo G. Prevalence of depressive symptoms in late pregnancy and postpartum. Acta Obstet Gynecol Scand 2001;80(3):251-255. https://doi.org/10.1034/j.1600 0412.2001.080003251.x

8. US Department of Health and Human Services. Healthy People 2010. With understanding and improving health and objectives for improving health. 2nd ed. Washington: US Governmen Printing Office, 2000

9. Boyd RC, Pearson JL, Blehar MC. Prevention and treatment of depression in pregnancy and the postnatal period-summary of a maternal depression roundtable: a US perspective. Arch Women's Ment Health 2002:4:79-82, http://doi.org/10.1007/s007370200003

10. Badr LK, Ayvazian N, Lameh S, Charafeddine L. Is the effect of postpartum depression on mother-infant bonding universal? Infant Behav Dev 2018;51:15-23. https://doi.org/10.1016/ . infbeh.2018.02.003

11. Kita S, Haruna M, Matsuzaki M, Kamibeppu K. Associations between intimate partner violence (IPV) during pregnancy, mother-to-infant bonding failure, and postnatal depressive symptom Arch Womens Ment Health 2016;19(4):623-634. https://doi.org/10.1007/s00737-016-0603-y
12. Netsi E, Pearson RM, Murray L, Cooper P, Craske MG, Stein A. Association of persistent and severe postnatal depression with child outcomes. JAMA Psychiatry 2018;75(3):247-253. https:// doi.org/10.1001/jamapsychiatry.2017.4363

13. Arifin SRM, Cheyne H, Maxwell M. Review of the prevalence of postnatal depression across cultures. AIMS Public Health 2018;5(3):260-295. https://doi.org/10.3934\%2Fpublicheal th. 2018.3.260

14. Cox JL, Holden JM, Sagovsky R. Detection of postnatal depression: Development of the 10-item Edinburgh postnatal depression scale. Br J Psych 1987;150:782-786. https://doi.org/10.1192/ bjp.150.6.782

15. Shakil A, Bardwell J, Sherin K, Sinacore JM, Zitter R, Kindratt TB. Development of Verbal HITS for intimate partner violence screening in family medicine. Fam Med 2014; 46(3):180-185.

16. Cohen S, Mermelstein R, Kamarck T, Huberman HM. Measuring the perinatal componen of social support. In Samson IG, Samson BR, eds. Social support: Theory, Research and Applications. The Hague: MartinusNiijhoff, 1985.

17. Owoeye AO, Aina OF, Morakinyo O. Risk factors of postpartum depression and EPDS scores in a group of Nigerian women. Trop Doct 2006;36(2):100-103. https://doi. org/10.1258/004947506776593341

18. Parsons CE, Young KS, Rochat TJ, Kringelbach ML, Stein A. Postnatal depression and its effects on child development: A review of evidence from low- and middle-income countries. Br Med Bulletin 2012;101(1):57-79. https://doi.org/10.1093/bmb/ldr047

19. Rochat TJ, Richter LM, Doll HA, Buthelezi NP, Tomkins A, Stein A. Depression among pregnant rural South African women undergoing HIV testing. JAMA 2006;295(12):1373-1378. https://doi. org/10.1001/jama.295.12.1376

20. Ramchandani PG, Richter LM, Stein A, Norris SA. Predictors of postnatal depression in an urban South African cohort. J Affective Dis 2009;113(3):279-284.

21. Lawrie TA, Hofmeyr GJ, de Jager M, Berk M. Validation of the Edinburgh Postnatal Depression Scale on a cohort of South African women. S Afr Med J 1998;88(10):1340-1344.

22. Carter JD, Mulder RT, Bartram AF, et al. Infants in a neonatal intensive care unit: Parental response. Arc Dis Child 2005; 90(2):F109-F113.

23. Singer LT, Salvator A, Guo S, et al. Maternal psychological distress and parenting stress after the birth of a very low-birth-weight infant. JAMA 1999;281:799-805. https://doi.org/10.1001/ jama.281.9.799

24. Evans MG, Phillippi S, Gee RE. Examining the screening practices of physicians for postpartum depression: Implications for improving health outcomes. Womens Health Iss 2015;25(6):703-710. https://doi.org/10.1016/j.whi.2015.07.003

25. Gurung B, Jackson LJ, Monahan M, Butterworth R, Roberts TE. Identifying and assessing the benefits of interventions for postnatal depression: a systematic review of economic evaluations. BMC Preg Child 2018;18(1):179. https://doi.org/10.1186/s12884-018-1738-9

26. Molenaar NM, Kamperman AM, Boyce P, Bergink V. Guidelines on treatment of perinatal depression with antidepressants. Austr New Zeal J Psych 2018;52(4):320-327. https://doi. org/10.1177/0004867418762057

27. Shama R, Tandon TR. A stitch in time saves nine: Untreated perinatal depression hurts future generations. Asian J Psychiat 2018;38:A1-A3. https://doi.org/10.1016/j.ajp.2018.11.009

28. Shrivastava SR, Shrivastava PS, Ramasamy J. Antenatal and postnatal depression A public health perspective. J Neurosci Rural Pract 2015;6(1):116-119. https://doi org/10.4103\%2F0976-3147.143218

29. Underwood L, Waldie K, D'Souza S, et al. A review of longitudinal studies on antenatal and postnatal depression. Arch Womens Ment Health 2016;19(5):711-720. https://doi.org/10.1007/ s00737-016-0629-1

30. Cooper PJ, Murray L. Fortnightly review: Postnatal depression. Br Med J 1998;316(7148):18841886. https://doi.org/10.1136\%2Fbmj.316.7148.1884

31. Netsi E, Pearson RM, Murray L, Cooper P, Craske MG, Stein A. Association of persistent and severe postnatal depression with child outcomes. JAMA Psych 2018;75(3):247-253. https://doi. org/10.1001/jamapsychiatry.2017.4363

32. Laurent H, Goodman SH, Stowe ZN, et al. Course of ante- and postnatal depressive symptoms related to mothers' HPA axis regulation. J Abnormal Psych 2018;127(4):404-416. http://doi.org/10.1037/abn0000348

Accepted 17 November 2019 